\title{
Biomedical Waste Management in Visakhapatnam with Future Perspective
}

\author{
Dr. Yashoda Tammineni
}

\begin{abstract}
Visakhapatnam is a very fast growing city heading towards metro status and is also enlisted by PM of India as a smart city. Visakhapatnam's urbanization process has been alarmingly fast making it a challenge for the state government to provide the much needed infrastructure. Of the many challenges that Visakhapatnam face, biomedical waste management is one of the critical issues. Biomedical waste management has recently emerged as an issue of major concern not only to hospitals, nursing home authorities but also to the environment. The entire practice of bio medical waste management was being carried out unsupervised. Lack of proper monitoring and regulation, hazardous bio medical waste are mixed with non-hazardous waste, making the entire waste hazardous. Such hazardous wastes because of inappropriate disposal/ treatment strategies are potentially infectious and present a potential hazard to public health and the environment. Effective and efficient waste segregation systems should be developed and implemented. Information with respect to risks involved in biomedical waste management practices have to be disseminated for public and general community.
\end{abstract}

Keywords: Biomedical waste management, Healthcare facilities, infectious diseases ,environment friendly manner, per norms of 2016 Biomedical waste amendment

\section{Introduction}

Visakhapatnam, known as "city of destiny" $\left(17^{\circ} 42^{\prime} \mathrm{N} 83^{\circ}\right.$ $15^{\prime}$ E) at an altitude of 18 feet above sea level with a population of 2,091,811 occupying $681.96 \mathrm{~km}^{2}$, is an industrial hub on the east coast of India and is home for people around the country. Visakhapatnam's urbanization process has been alarmingly fast making it a challenge for the state government to provide the much needed infrastructure. Of the many challenges that Visakhapatnam face, biomedical waste management is one of the critical issues. Biomedical waste management has recently emerged as an issue of major concern not only to hospitals, nursing home authorities but also to the environment.

The bio-medical wastes generated from health care units depend upon a number of factors such as waste management methods, type of health care units, occupancy of healthcare units, specialization of healthcare units, ratio of reusable items in use, availability of infrastructure and resources etc.

The proper management of biomedical waste has become a worldwide humanitarian topic today. Although hazards of poor management of biomedical waste have aroused the concern world over, especially in the light of its far- reaching effects on human, health and the environment. World Health Organization states that $85 \%$ of hospital wastes are actually non-hazardous, whereas $10 \%$ are infectious and 5\% are non- infectious but they are included in hazardous wastes. About $15 \%$ to $35 \%$ of Hospital waste is regulated as infectious waste. This range is dependent on the total amount of waste generated (Glenn and Garwal , 1999).

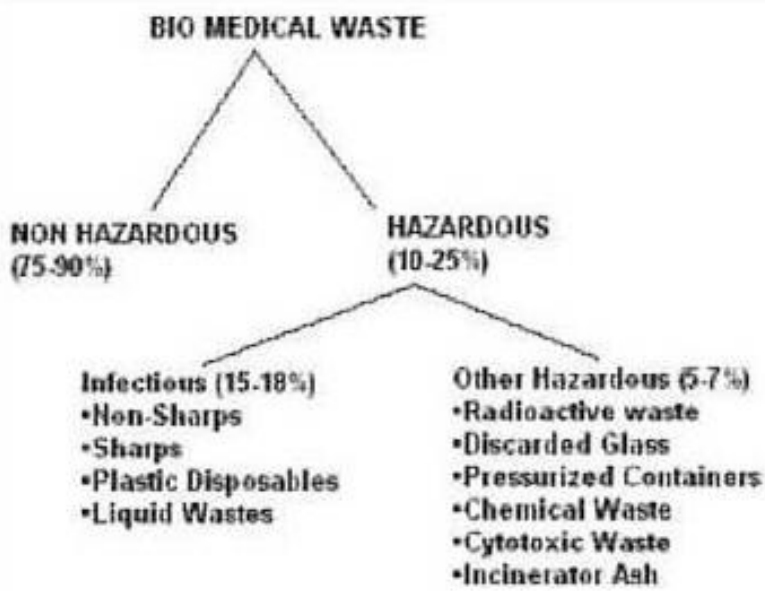

A major issue related to current Bio- Medical waste management in many hospitals is that the implementation of Bio-Waste regulation is unsatisfactory as some hospitals are disposing of waste in a haphazard, improper and indiscriminate manner. Lack of segregation practices, results in mixing of hospital wastes with general waste making the whole waste stream hazardous. Inappropriate segregation ultimately results in an incorrect method of waste disposal.

Inadequate Bio-Medical waste management thus will cause environmental pollution, unpleasant smell, growth and multiplication of vectors like insects, rodents and worms and may lead to the transmission of diseases like typhoid, cholera, hepatitis and AIDS through injuries from syringes and needles contaminated with human.

Various communicable diseases, which spread through water, sweat, blood, body fluids and contaminated organs, are important to be prevented. The Bio Medical Waste scattered in and around the hospitals invites flies, insects, rodents, cats and dogs that are responsible for the spread of communication disease like plague and rabies. Rag pickers in the hospital, sorting out the garbage are at a risk of getting tetanus and HIV infections. The recycling of disposable syringes, needles, IV sets and other article like glass bottles without proper sterilization are responsible for Hepatitis, $\mathrm{HIV}$, and other viral diseases. 


\section{International Journal of Science and Research (IJSR) \\ ISSN: 2319-7064}

ResearchGate Impact Factor (2018): 0.28 | SJIF (2018): 7.426

The problem of biomedical waste disposal in the hospitals and other healthcare establishments has become an issue of increasing concern, promoting hospital administration to seek new ways of scientific, safe and cost effective management of the waste. The need of proper biomedical waste management system is of prime importance and is an essential component of quality assurance in hospitals.

\section{Insight on the practices of Biomedical waste management:}

To make the study more authentic and valid, it is highly essential

- To investigate and make a survey regarding definitions, characterization and classification of biomedical waste, associated risks by visiting various hospitals of Visakhapatnam bringing minimum observance that any health care facilities should comply with, key management principles, sound treatment and disposal technologies applicable to each category of waste.

- To estimate the total outcome of the biomedical waste generated from various hospitals and the possible health risks associated with the biomedical waste.

- To isolate air and water samples from the contaminated areas of Visakhapatnam and collection of incinerated ash samples from dumping yard for the examination of airborne and water borne microbes.

- To study the qualitative and quantitative analysis of the biomedical waste.

- To provide guidance to develop a strategy to implement a biomedical waste management plan through reinforcement of the collaboration between the central, regional and municipal/local authorities to improve the health care waste management practices and to find out pragmatic solutions.

\section{Interventions proposed/ suggested solutions and alternatives \\ It is proposed to develop a systematic method to collect biomedical waste as per colored bins segregation proposed as per norms of 2016 Biomedical waste amendment since the different types of wastes generated from different departments of hospitals are not being disposed properly and thus leading to the spread of various infectious diseases especially the nuclear wastes are of much concern which are carcinogenic that are being disposed from the nuclear medicine departments.}

Methods to be popularized to masses, training schedules, methods of imparting training

It is highly essential to train the persons of the hospital management in proper collection and transportation of discarded wastes, chemical wastes, animal waste, liquid wastes, human anatomical wastes and incinerated wastes as per the norms. It is essential to train the people of management of incinerators and deep burying of the ash.

Expected deliverables/ outcomes highlighting societal benefits

The Proposed study will yield the practical methods in collecting biomedical waste so that the hospital surroundings will not be affected or contaminated and helps in preventing epidemics. This will certainly benefit in the prevention of infectious diseases and eradication of environmental pollution.

\section{Proposed utility of the outcomes}

The outcome of the study definitely enhances the need for the hospital managements to follow the regular procedures in the process of disposal of biomedical waste management since these details of investigated study will be published in journals and news papers that make even public also more aware of disposing the biomedical waste whatever they use at their homes.

\section{Conclusions and Recommendations}

The present scenario reveals the lack of knowledge in different aspects of biomedical waste management. Healthcare facilities and government should work together to develop standard procedures for BMW management. The segregation and handling of waste at the source is the key step in managing biomedical waste and prompt reduction, reuse and recycling methods should be considered in proper perspectives. The challenge before us, therefore, is to scientifically manage growing quantities of biomedical waste that go beyond past practices and strictly implement BMW rules by all health care facilities to ensure safety and protection to all health care staff and housekeeping staff. It is likely that public sector and the community take equal responsibility to manage biomedical waste in a safer and environment friendly manner. 